\title{
sciendo
}

\author{
Current Issues in Pharmacy and Medical Sciences \\ Formerly ANNALES UNIVERSITATIS MARIAE CURIE-SKLODOWSKA, SECTIO DDD, PHARMACIA \\ journal homepage: http://www.curipms.umlub.pl/
}

\section{Reversal effect of Solanum dasyphyllum against rotenone-induced neurotoxicity}

\author{
Omotayo B. Ilesanmi ${ }^{1,2 *}$ ๑ , Obade Efe ${ }^{1}$, Temitope T. Odewale 3 , Francis O. Atand ${ }^{4}$, \\ Esther F. Adeogun ${ }^{3}$, Afolabi C. Akinmoladun ${ }^{1}$, Tolulope M. Olaleye ${ }^{1}$
}

\author{
${ }^{1}$ Department of Biochemistry, School of Sciences, Federal University of Technology Akure, Akure Ondo State, Nigeria \\ ${ }^{2}$ Department of Biochemistry, Faculty of Science, Federal University Otuoke, Yenagoa, Bayelsa State, Nigeria \\ ${ }^{3}$ Department of Biochemistry, Faculty of Life Sciences, University of Benin, Edo State, Nigeria \\ ${ }^{4}$ Department of Biochemistry, Faculty of Natural Sciences, Kogi State University, Anyigba, Nigeria
}

\begin{tabular}{|c|c|}
\hline ARTICLE INFO & ABSTRACT \\
\hline $\begin{array}{l}\text { Received } 17 \text { February } 2020 \\
\text { Accepted } 04 \text { June } 2020\end{array}$ & $\begin{array}{l}\text { We earlier reported the protective effect of Solanum dasyphyllum against cyanide } \\
\text { neurotoxicity. In furtherance to this, we investigated the protective effect of } S \text {. dasyphyllum }\end{array}$ \\
\hline $\begin{array}{l}\text { Keywords: } \\
\text { rotenone, } \\
\text { mitochondria respiratory } \\
\text { enzymes, } \\
\text { oxidative stress, } \\
\text { Solanum dasyphyllum, } \\
\text { brain. }\end{array}$ & $\begin{array}{l}\text { against rotenone, a chemical toxin that causes brain-related diseases. Mitochondria } \\
\text { fraction obtained from the brain of male Wistar rats was incubated with various solvents } \\
\text { (hexane, dichloromethane, ethylacetate, and methanol) extracts of } S \text {. dasyphyllum before } \\
\text { rotenone exposure. Mitochondria respiratory enzymes (MRE) were evaluated along with } \\
\text { markers of oxidative stress. The inhibition of MRE by rotenone was reversed by treatment } \\
\text { with various fractions of } S \text {. dasyphyllum. The oxidative stress induced by rotenone was } \\
\text { also reversed by fractions of } S \text {. dasyphyllum. In addition, the ethylacetate fraction of } \\
\text { S. dasyphyllum was most potent against rotenone-induced neurotoxicity. In conclusion, } \\
\text { S. dasyphyllum is rich in active phytochemicals that can prevent some neurotoxic effects } \\
\text { of rotenone exposure. Further study can be done in an in vivo model to substantiate our } \\
\text { results. }\end{array}$ \\
\hline
\end{tabular}

\section{INTRODUCTION}

Exposure to rotenone as a result of its usage as pesticides has been linked to the development of neurodegenerative diseases such as Parkinson's disease (PD) [1]. The mechanism of rotenone toxicity is associated with increased generation of reactive oxygen species (ROS). Information gathered from the study of neurodegenerative diseases showed that mitochondria dysfunction, alteration of neurochemicals, and oxidative stress are some of the pathological features observed in rotenone poison $[2,3]$.

Medicinal plants are becoming good alternatives in the treatment and management of various diseases in the urban area of sub-Saharan Africa, Nigeria included [4]. Their efficacy and ability to treat more than one ailment further attracts researchers in the field of phytomedicine and phytochemistry to study them, the bioactive compounds responsible, and their mechanism of action [5].

Solanum dasyphyllum belongs to the Solanaceae family. It is rich in bioactive phytochemicals such as glycoalkaloids,

\footnotetext{
* Corresponding author

e-mail: ilesanmiob@fuotuoke.edu.ng
}

glycosides, polyphenol and flavonoids [6-8]. The plant is used ethnobotanically for the treatment of diarrhea, wound healing, antispasmolytic, anticonvulsant, and neuroprotective activities [9-11]. We earlier reported the protective effect of $S$. dasyphyllum extracts against $\mathrm{KCN}$-induced neurotoxicity [12] in furtherance to the evaluation of its neuroprotective potentials, we investigated the neuroprotective potential of S. dasyphyllum against rotenone neurotoxicity.

\section{MATERIALS AND METHODS}

\section{Plant collection and preparation of extract}

Leaves of Solanum dasyphyllum (eggplant) were harvested and authenticated at the Botany Department, Obafemi Awolowo University, Ile Ife, Nigeria. The leaves were airdried to constant weight and pulverized. The pulverized sample was dissolved in $80 \%$ aqueous methanolic extract for $72 \mathrm{hrs}$, filtered, and lyophilized to obtain crude extract. The crude extract was further partitioned with hexane, dichoroform, ethylacetate, and methanol as described by [12] to obtain hexane fraction of $S$. dasyphyllum (HSD), dichloromethane fraction of $S$. dasyphyllum (DSD), ethylacetate 
fraction of $S$. dasyphyllum (ESD) and the methanolic fraction of $S$. dasyphyllum (MSD) fractions, respectively.

\section{Experimental Animals}

Rats used for the experiment were kept in a conducive environment according to the guidelines of the National Institute of Health for laboratory animals and approved by the departmental committee on animal care and handling.

\section{Preparation of brain homogenates and treatments.}

The brain was carefully excised from the rats, rinsed with $1.15 \% \mathrm{KCl}$ and carefully dissected on ice to separate the cerebellum and cortex. Both were weighed and homogenized together to obtain the homogenate used for the experiment.

\section{Preparation of mitochondria pellet (MP)}

Brain mitochondria fraction were prepared according to the method described by [13]. Briefly, homogenate obtained from rat brain were subjected to differential centrifugation in an isolation buffer to obtain a mitochondria pellet that was suspended in the isolation buffer at a concentration of $10 \mathrm{mg} / \mathrm{ml}$ for experimental purpose.

\section{Experimental design}

Exposure of brain homogenates to rotenone was according to the modified method of [14]. Briefly, negative control consisted of the brain homogenate and buffer, positive control was brain homogenate and rotenone (4 mM) [15], while the treatment group was brain homogenate incubated with varying concentrations $(5-50 \mu \mathrm{g} / \mathrm{ml})$ of solvent fractions for $30 \mathrm{~min}$ before incubation with rotenone for another $30 \mathrm{~min}$ at $37^{\circ} \mathrm{C}$.

\section{Oxidative stress}

The lipid peroxidation (LPO) inhibitory activity was evaluated by measuring the formation of thiobarbituric acid (TBA) reactive substances (TBARS) according to the method of [16] and described by [12]. PC content in the brain regions was determined according to the method of [17] and described by [12].

\section{Evaluation of Acetylcholineesterase (AChE) Activity}

The activity of AChE was assessed based on the modified method of [18]. Briefly, the reaction mixture contained $0.1 \mathrm{ml}$ DTNB and $2.6 \mathrm{ml}$ phosphate buffer (0.1 M, pH 8.0), $0.04 \mathrm{ml}$ of brain homogenate and incubated for $5 \mathrm{~min}$. Acetylthiocholine iodide $(0.075 \mathrm{M})$ was added after incubation and the rate of hydrolysis was measured at $420 \mathrm{~nm}$ continuously for $3 \mathrm{~min}$. the activity of AChE was calculated and expressed in $\mu \mathrm{mol}^{-1} \mathrm{~min}^{-1}$ mgprotein ${ }^{-1}$.

Evaluation of NADH - succinate dehydrogenase (NSD) activity, NADH -succinate reductase (NSR) and NADHcytochrome c reductase (NCR) activity

Procedure: NCR and NSR activities were spectrophotometrically measured as described in [19]. Briefly, the mitochondria pellet $(0.1 \mathrm{mg})$ was incubated with $0.5 \mu \mathrm{M}$ of rotenone with or without various fractions of $S$. dasyphyllum for a period of $1 \mathrm{~h}$., the reaction mixture (RM) was then added to phosphate buffer $(0.1 \mathrm{M}, \mathrm{pH} 7.4)$ containing
$\mathrm{NADH}(0.2 \mathrm{mM})$ and $\mathrm{KCN}(1 \mathrm{mM})$. Enzyme activity was initiated by the addition of $0.1 \mathrm{mM}$ cytochrome $\mathrm{C}$ to give a final volume of $1 \mathrm{ml}$. A decrease in absorbance was monitored for $3 \mathrm{~min}$ at $550 \mathrm{~nm}$. The activity of the enzyme was expressed as nmol cytochrome $\mathrm{C}$ reduced $/ \mathrm{min} / \mathrm{mg}$ protein $273(€-19.6 / \mathrm{mM} / \mathrm{cm})$. To determine the activity of SCR, the substrate succinate $(20 \mathrm{mM})$ was used.

The activity of NSD was assessed as described by [20]. Briefly, $0.05 \mathrm{ml}$ of the RM was incubated with $0.8 \mathrm{ml}$ phosphate buffer $(50 \mathrm{mM}), 0.1 \mathrm{ml}$ sodium succinate $(0.01 \mathrm{M})$ and $0.025 \mathrm{ml} \mathrm{p}$-iodonitro tetrazolium (INT) $(2.5 \mu \mathrm{g} / \mathrm{ml})$ at room temperature for 10 minutes. After incubation, $0.5 \mathrm{ml}$ TCA (10\%) and $0.5 \mathrm{ml}$ ethylacetate/ethanol/TCA (5:5:1, v: v: w) was added. Absorbance was read at $490 \mathrm{~nm}$. Results are expressed as nmol of INT/mg protein.

\section{Evaluation of Total Protein Concentration}

Total protein level was determined using an assay kit from Randox Laboratory Ltd, Antrim, UK, following the instructions of the manufacturer.

\section{Statistical analysis}

Results were expressed as mean \pm standard deviation (SD). Statistical differences between means were determined by one way analysis of variance (ANOVA) followed by Duncan's test. $\mathrm{p}<0.05$ was considered statistically significant.

\section{RESULTS}

Rotenone significantly elevates the oxidation of lipids in comparison with control $(\mathrm{p}<0.01)$. This was significantly prevented by treatment with various extracts of $S$. dasyphyllum (SD). The table reveals that ESD was the most active extract in comparison to other solvent extracts, while the lowest activity was observed in HSD as compared to other solvent extracts (Figure 1).

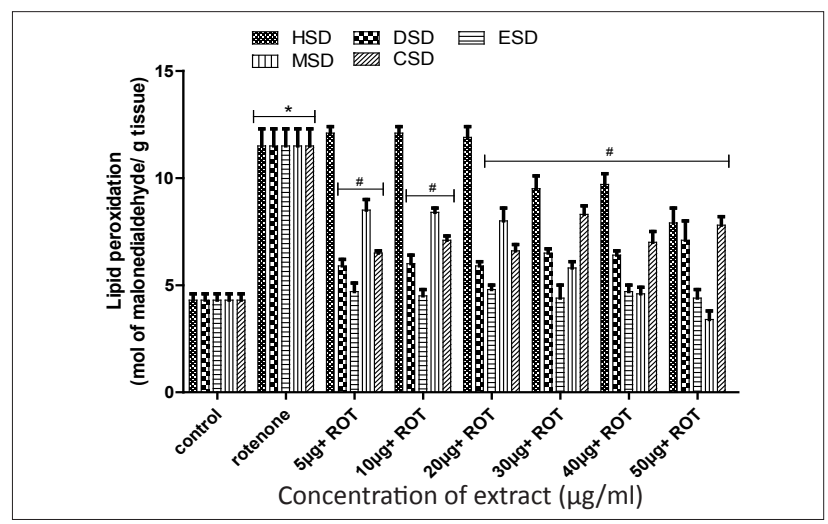

Results are presented as mean \pm standard deviation $(n=5) .{ }^{*} p<0.05$ : ROT vs Control, $+p<0.05$ : ROT vs Treatment. HSD (Hexane extract of S. dasyphyllum); DSD (Dichloromethane extract of S. dasyphyllum); ESD (Ethyl Acetate extract of S. dasyphyllum); MSD (Methanol extract of S. dasyphyllum); CSD (Crude extract of $S$. dasyphyllum)

Figure 1. Protective effect of solvent extracts of Solanum dasyphyllum on lipid peroxidation in the cerebrocortex region of rats exposed to rotenone neurotoxicity

Figure 2 summarized the effect of solvent extracts of SD on GSH concentration in the cerebrocortex of male wistar rats. Rotenone caused a significant decrease in GSH 
levels in comparison to control $(\mathrm{p}<0.05)$. Varying effects of solvent extracts of SD were observed. At low concentration, all the extracts had no significant effect on rotenone-induced decreased in GSH concentration. However, at high concentrations, all the solvent extracts significantly increased the concentration of GSH in the cerebrocortex in comparison to the rotenone-treated group $(\mathrm{p}<0.05)$. The table also reveals that DSD extract was the most potent extract as compared to other extracts.

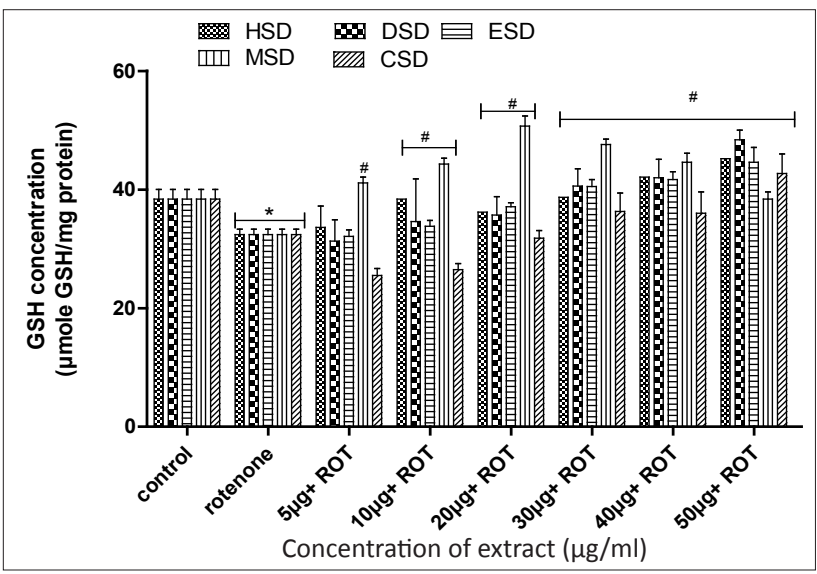

Results are presented as mean \pm standard deviation $(n=5)$. $* p<0.05$ : Control vs ROT, \# p<0.05: ROT vs Treated. HSD (Hexane extract of S. dasyphyllum); DSD (Dichloromethane extract of $S$. dasyphyllum); ESD (Ethyl Acetate extract of S. dasyphyllum); MSD (Methanol extract of S. dasyphyllum); CSD (Crude extract of S. dasyphyllum)

Figure 2. Protective effect of solvent extracts of Solanum dasyphyllum on reduced glutathione (GSH) concentration in the cerebrocortex region of rats exposed to rotenone neurotoxicity

Figure 3 summarizes the effect of solvent extracts of $\mathrm{SD}$ on monoamine oxidase activity induced by rotenone. Rotenone caused a significant increase in the activity of monoamine oxidase as compared to the control $(\mathrm{p}<0.01)$. All the solvent extracts significantly reverse the rotenoneinduced activity of MAO at all concentrations. Comparing the solvent extract, the ESD was more potent than the other extracts.

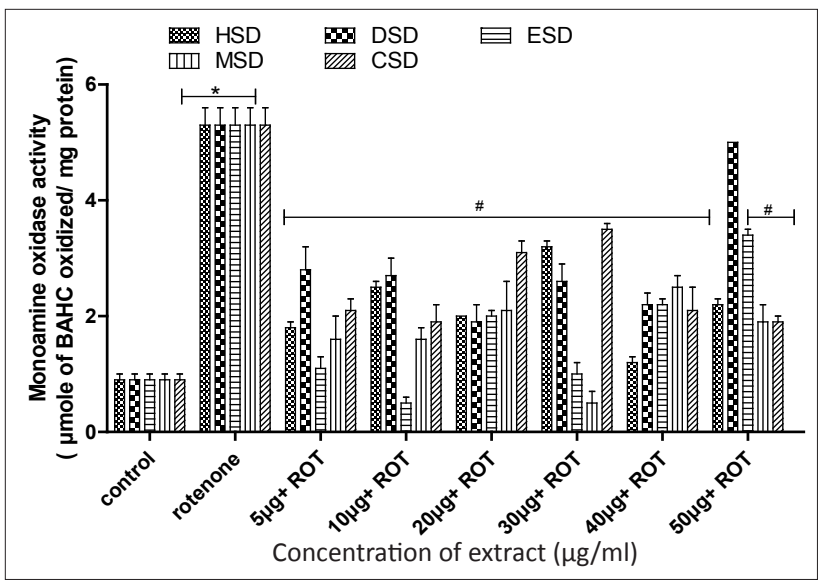

Results are presented as mean \pm standard deviation $(n=5) . * p<0.05$ : Control vs ROT, \# p<0.05: ROT vs Treated. HSD (Hexane extract of S. dasyphyllum); DSD (Dichloromethane extract of S. dasyphyllum); ESD (Ethyl Acetate extract of S. dasyphyllum); MSD (Methanol extract of S. dasyphyllum); CSD (Crude extract of S. dasyphyllum)

Figure 3. Protective effect of solvent extracts of Solanum dasyphyllum on monoamine oxidase (MAO) activity in the cerebrocortex region of rats exposed to rotenone neurotoxicity
Rotenone significantly increases the PC level as compared to the control $(\mathrm{p}<0.05)$. All the concentrations of the solvent extracts significantly reverse the increased level of PC induced by rotenone. As observed in the other results, ESD shows the most potent solvent extracts as compared to the other extracts (Figure 4).

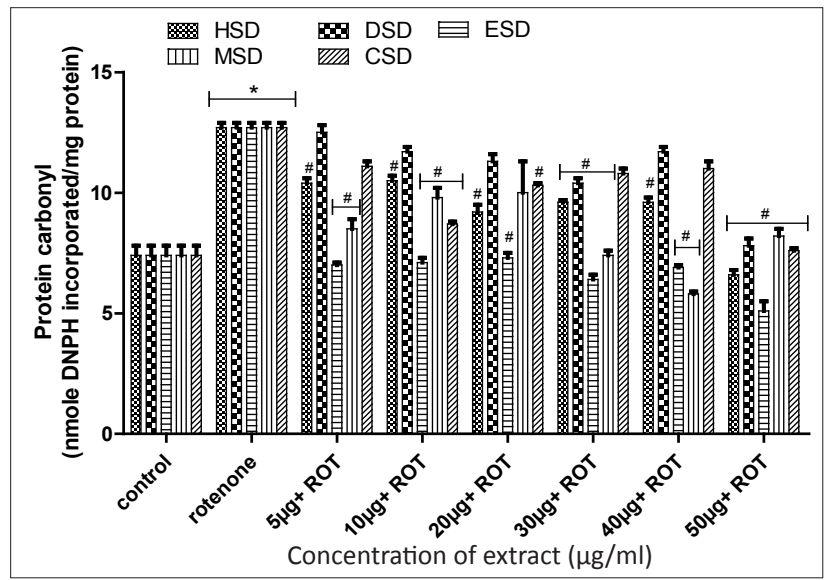

Results are presented as mean \pm standard deviation $(n=5)$. ${ }^{*} p<0.05$ : Contro vs ROT \# p<0.05: ROT vs Treated. HSD (Hexane extract of S. dasyphyllum); DSD (Dichloromethane extract of $S$. dasyphyllum); ESD (Ethyl Acetate extract of S. dasyphyllum); MSD (Methanol extract of S. dasyphyllum); CSD (Crude extract of $S$. dasyphyllum)

Figure 4. Protective Effect of solvent extracts of Solanum dasyphyllum on protein carbonyl (PC) concentration in the cerebrocortex region of rats exposed to rotenone neurotoxicity

In the cerebrocortex, exposure to rotenone significantly elevated acetylcholinesterase activity as compared to the control $(\mathrm{p}<0.05)$. All the solvent extracts at all concentrations administered significantly decreased the activity apart from ESD. Also, all the extracts seem to be more effective at lower concentrations (Figure 5).

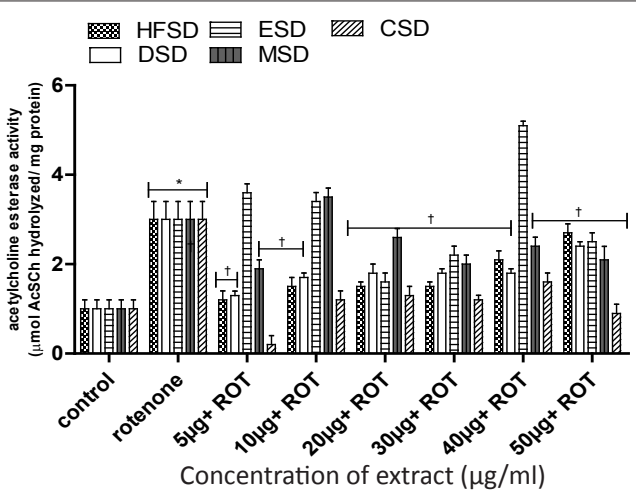

Results are presented as mean \pm standard deviation. $(n=5) . * p<0.05$ : ROT vs Control, $+p<0.05$ : ROT vs Treated. HSD (Hexane extract of $S$. dasyphyllum) DSD (Dichloromethane extract of S. dasyphyllum); ESD (Ethyl Acetate extract of S. dasyphyllum); MSD (Methanol extract of S. dasyphyllum); CSD (Crude extract of S. dasyphyllum)

Figure 5. Anticholinesterase activities of solvent extracts of Solanum dasyphyllum in the cerebrocortex region of rats exposed to rotenone neurotoxicity

Rotenone treatment significantly inhibits the activity of NADH-cytochrome $\mathrm{c}$ reductase $(\mathrm{p}<0.001)$ in the cerebrocortex as compared to the control. All the extracts significantly prevented the inhibitory effect of rotenone. We also observed that all the solvent extracts increase the activity of the enzyme as compared to the control - all showing a potential to increase the expression of the enzyme in the cerebrocortex (Figure 6). 


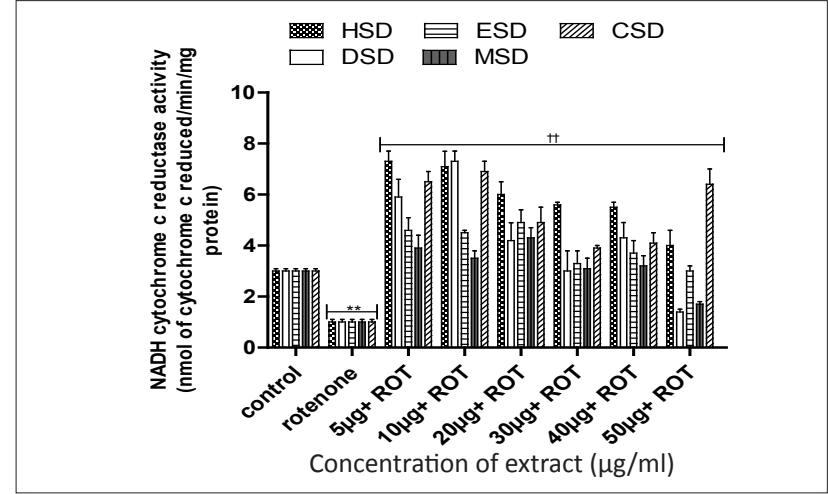

Results are presented as mean \pm standard deviation $(n=5) . * * p<0.001$ : ROT vs Control, $++p<0.001$ : ROT vs Treated. HSD (Hexane extract of S. dasyphyllum); DSI Concentration of extract ( $\mu \mathrm{g} / \mathrm{ml}$ ) dasyphyllum); ESD (Ethyl Acetate extract of S. dasyphyllum); MSD (Methanol extract ESD (Ethyl Acetate extract of S. dasyphyllum); MSD (Me
of S. dasyphyllum); CSD (Crude extract of S. dasyphyllum)

Figure 6. Effect of solvent extracts of S. dasyphyllum on NADH -cytochrome $\mathrm{c}$ reductase activity in rat cerebrocortex exposed to Rotenone

Rotenone also caused a significant reduction in the activity of succinate cytochrome c reductase in the cerebrocortex as compared to the control $(p<0.05)$. However, there were variations in the protective effect of the various extracts, HSD, DSD, and CSD were able to significantly reverse the inhibitory effect of rotenone on the enzyme, while, ESD and MSD showed no protective effect against rotenone inhibition of succinate cytochrome c reductase (Figure 7).

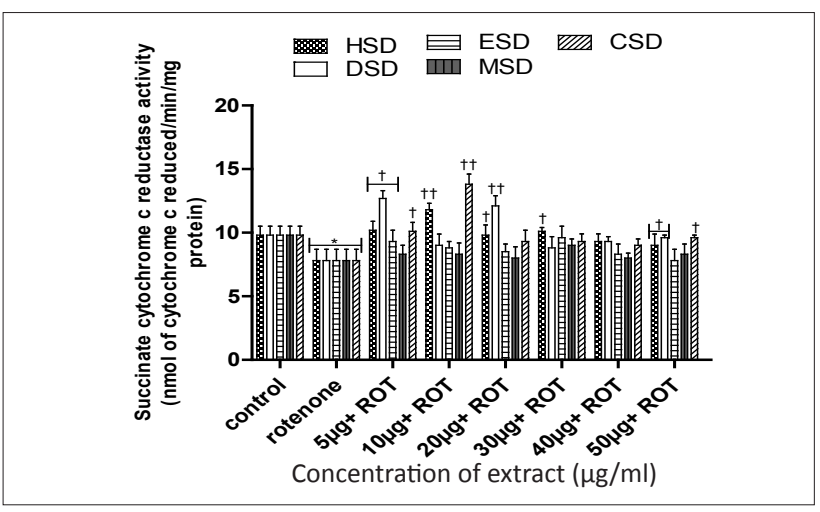

Results are presented as mean \pm standard deviation $(n=5) . * p<0.05$ : ROT vs Control, $++p<0.05$ : ROT vs Treated. HSD (Hexane extract of S. dasyphyllum); DSD (Dichloromethane extract of S. dasyphyllum); ESD (Ethyl Acetate extract of S. dasyphyllum); MSD (Methanol extract of S. dasyphyllum); CSD (Crude extract of $S$. dasyphyllum)

Figure 7. Effect of solvent extracts of $S$. dasyphyllum on Succinate - cytochrome $\mathrm{c}$ reductase in rat cerebrocortex exposed to potassium Rotenone

Rotenone causes a significant change in the activity of $\mathrm{NADH}$-succinate dehydrogenase as compared to the control $(\mathrm{p}<0.001)$. However, it was only DSD and MSD were able to protect against rotenone reduction of the activity of the enzyme (Figure 8).

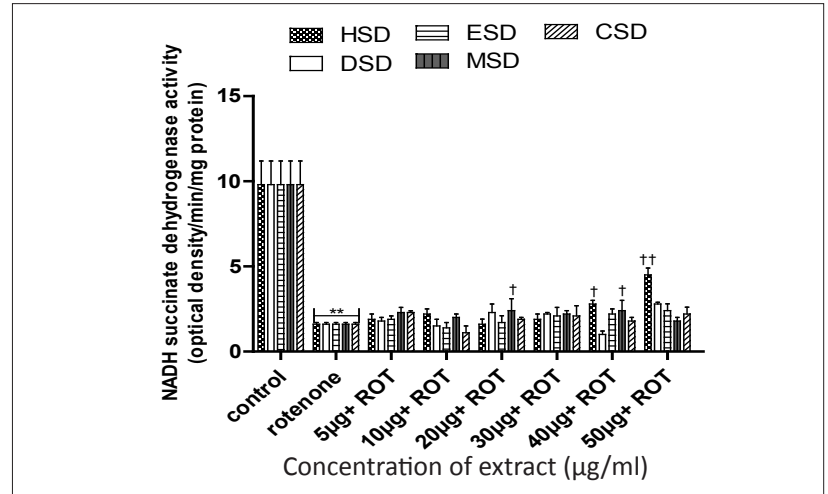

Results are presented as mean \pm standard deviation $(n=5) . * * p<0.001$ : ROT vs Control, $+p<0.05$ : ROT vs Treated. $++p<0.001$ : ROT vs Treated. HSD (Hexane extract of $S$. dasyphyllum); DSD (Dichloromethane extract of S. dasyphyllum); ESD (Ethyl Acetate i DStract of S. dasyphyllum); MSD (Methanol extract of S. dasyphyllum); CSD (Crude extract of S. dasyphyllum) Figure 8. Effect of $S$. dasyphyllum on NADH- succinate dehydrogenase in rat cerebrocortex exposed to Rotenone

\section{DISCUSSION}

The pharmacology and bioactive compounds in plants have been reported to depend on the nature of solvents used in dissolving the plant. While some natural compounds may be abundant in some solvent extracts, they may be absent or low in other solvent extracts [21-24]. Polar solvents such as ethanol and methanol are used in the extraction of phenolic compounds, saponin, and glycosidic derivatives, while flavonoids, steroids, and alkaloids are extracted with a non-polar solvent such as n-hexane and dichloromethane [24].

Solanum dasyphyllum is a plant that is commonly used as an anticonvulsant drug. It is rich in various phytochemicals that have been reported to possess neuroprotective and cardioprotective activities. Some of the natural compounds isolated from the plant include scopolectin and coumarin. Earlier, we reported the neuroprotective activity of various extracts of $S$. dasyphyllum against $\mathrm{KCN}$ (a mitochondria toxin). Phytochemical screening of the various solvent fractions showed that flavonoids were the most abundant in ESD, alkaloids and steroids are the most abundant in HSD, while the MSD contains saponin, steroids, terpenoids, flavonoids, and glycosides in small, but equal proportions (unpublished). This current work reported the neuroprotective effect of various solvent extracts of $S$. dasyphyllum against rotenone (a mitochondria toxin that is used to model neurodegenerative disease).

Acetylcholinesterase (AChE), one of the key enzymes implicated in the etiology of Alzheimer's disease (AD), regulates the transmission of impulse in the neurons. The inhibition of this enzyme is a major indicator of drugs/ natural compounds in their potential to treat AD. It has been reported that Solanum species are rich in compounds that inhibit AChE activity [25,26]. While all the solvent extracts at a moderate concentration significantly reversed the rotenone-induced elevation of AChE, HSD and CSD showed the most consistent at different concentration in inhibiting the activity of AChE. Phytochemical screening of HSD shows an abundance of alkaloids and steroids. Thus, the anticholinesterase activity of $S$. dasyphyllum might not only be from the contained flavonoids and polyphenols, but alkaloids and sterols can also contribute greatly to its 
anticholinesterase activity [26-28]. The anticholinesterase activity of $S$. dasyphyllum extract can add to the repertoire of natural products with the potential to treat some neurodegenerative diseases [29].

Rotenone is becoming a major neurotoxic compound used in testing the neuroprotective effect of natural compounds $[30,31]$. The mechanism of toxicity involves inhibition of the mitochondrial respiratory enzyme (complex I in particular). It is believed that inhibition of complex I leads to other pathology observed in rotenone-induced neurotoxicity [32]. These pathologies include; oxidative damage to protein, lipid, and nucleic acids, generation of ROS, apoptosis and formation of Lewy bodies [33].

\section{Mitochondria Respiratory Enzymes (MRE)}

Apart from the complex I enzyme that is generally inhibited by rotenone. Rotenone also has a negative effect on the activity of other respiratory enzymes, including succinate cytochrome $\mathrm{c}$ reductase and NADH cytochrome $\mathrm{C}$ reductase [34]. In the present study, rotenone caused a significant inhibition of NADH cytochrome c reductase, and NADH succinate dehydrogenase activity as compared to the control. Moderate inhibition of succinate cytochrome $\mathrm{c}$ reductase was also observed. The implication of this observation can be explained in a cascade of events whereby rotenone inhibition of complex I can affect other respiratory enzymes, leading to electron leakage from mitochondria [35], resulting in increased generation of ROS, which will further aggravate the inefficiency of mitochondrial respiratory enzymes [34].

The result showed that all the solvent extract had a varying effect on rotenone-induced alteration in the MRE. Indeed, all the solvents extract completely reversed the rotenone-altered inhibition of cytochrome $\mathrm{C}$ reductase, while the most potent extract was HSD. All the extracts also significantly reversed the moderate inhibition of succinate cytochrome $\mathrm{C}$ reductase by rotenone, except MSD, which had no significant effect. However, the most potent extract was the crude and DCM extract of SD. Though compounds from DCM extracts generally lack antioxidant properties, they are rich in cytotoxic, anti-apoptotic properties [36]. In the present study, rotenone caused a significant increase in the level of malonedialdehyde (MDA). This is consistent with the general report of the pro-oxidation effect of rotenone [14]. The richness of $S$. dasyphyllum in phytochemicals with antioxidant properties has been reported by several authors $[6,8,12]$. All the solvent extracts of $S$. dasyphyllum significantly diminished the MDA level. The highest potency observed for EASD and MSD can be linked to the abundance of both free and combined forms of bioactive flavonoids and polyphenols in the solvent [6]. Reduced glutathione (GSH) is the important antioxidant molecule in the brain, the depletion of this important molecule can be deleterious. A low level of GSH has been reported in patients suffering from various types of neurological disorders [37]. GSH is a major barrier to the pro-oxidative activities of various toxins (rotenone included) [38]. GSH also operates by keeping the homeostatic status of thiol-containing protein and enzymes, keeping them active for a longer period. Rotenone exhibited its pro-oxidative activities by depleting the brain concentration of GSH as compared to control.
All the solvent extracts of $S$. dasyphyllum caused a significant increase in GSH concentration as compared to the rotenone group. Not only that, but the ability of $S$. dasyphyllum to enhance GSH level was also observed, as the concentration of GSH was significantly higher than the control.

MAO is a pro-oxidative enzyme that increased the level of ROS production in the brain. Moreover, it is involved in the depletion of neurotransmitters, an observable feature in neurotransmitter related disorders $[39,40]$. There is an increase in the search of MAO-inhibitors in the treatment and management of neurodegenerative diseases [41]. The significant increase in MAO activity induced by rotenone was reversed by all the solvent extracts of $S$. dasyphyllum. ESD and MSD was also the most potent extract, they further inhibited the activity of MAO when compared to control. Protein carbonyl (PC) is one of the major markers of oxidative activity of toxicants or biomolecules. The formation of PC reflects abnormal degradation of functional proteins and inefficient machinery to regular damaged protein $[17,42]$. Rotenone induced a significant increase in PC formation as compared to the control. All the solvent extracts, of S. dasyphyllum, however, reversed the PC inhibitory effect of rotenone. As observed in all the other assays, ESD was the most potent of all the solvent extracts.

\section{CONCLUSION}

The results revealed that all the solvent extracts of S. dasyphyllum significantly prevent rotenone-induced inhibition of mitochondria respiratory enzymes, inflammation, neurochemical as well as oxidative stress in rat brain. The ethylacetate fraction was the most potent solvent fractions and further work can be conducted on this fraction for identification and structural elucidation of the bioactive compounds.

\section{CONFLICT OF INTEREST}

The authors declare that they have no conflict of interest

\section{ETHICAL APPROVAL}

The research was carried out in the Phytomedicine, Molecular and Toxicology Unit of Department of Biochemistry, School of Sciences, Federal University of Technology Akure, Akure Ondo State, Nigeria.

All procedures used during the execution of this experiment dully followed the animal care guide of the Animal care Unit of the Department of Biochemistry, Federal University of Technology Akure, Ondo State, Nigeria.

\section{ORCID iDs}

Omotayo B. Ilesanmi (Dhttps://orcid.org/0000-0003-2345-0461

\section{REFERENCE}

1. Park SE, Sapkota K, Choi JH. et al. Rutin from Dendropanax morbifera Leveille protects human dopaminergic cells against rotenone-induced cell injury through inhibiting JNK and p38 MAPK signaling. Neurochem Res. 2014;39(4):707-18.

2. Hisahara $S$, Shimohama S. Toxin-induced and genetic animal models of Parkinson's disease. Parkinsons Dis. 2011;2011:9517-9. 
3. Enogieru AB, Haylett W, Hiss DC, Bardien S, Ekpo OE. Rutin as a potent antioxidant: implications for neurodegenerative disorders. Oxi Med Cell Longev. 2018;ID 6241017:1-17.

4. Doughari JH. Phytochemicals: Extraction methods, basic structures and mode of action as potential chemotherapeutic agents, phytochemicals - A global perspective of their role in nutrition and health. [http://www.intechopen.com/books/phytochemicalsa-global-perspective-of-their-role-in-nutrition-andhealth/ phytochemicals-extraction methods-basic-structures-and-modeof-action-as-potentialchemotherapeutic]

5. Renaud J, Martinol M. Resveratrol as a protective molecule for neuroinflammation: A review of mechanisms. Curr Pharm Biotechnol. 2014;15:1-12.

6. Adesina SK. Constituents of Solanum Dasyphyllum fruit. J Nat Prod. 1985;48(1):147.

7. Ali Z, Xu ZL; Zhang DY, He XL, Bahadur L, Yi XY. Molecular diversity analysis of eggplant (Solanum melongena) genetic resources. Genet Mol Res. 2013;10(2):1141-55.

8. Ajayi IA, Ojelere O. Evaluation of the antimicrobial properties of the ethanolic extracts of some medicinal plant Seeds from SouthWest Nigeria. IOSR-JPBS. 2014;9(4):80-5.

9. Coune C, Denoel A. Etude phytochimique des solanaceae d'afrique centrale i. Les alcalo deds e Solanum dasyphyllum. Planta Med. 1975;28:168-71.

10. Puyvelde LV, Geysen D, Ayobangira F, Nakizamungu E, Nswimiyimana A, Kalisa A. screening of medicinal plants of Rwanda for Acaricidal activity. J Ethnopharmacol. 1985;13:209-15.

11. Clementino-Neto J, Pereira JC, Vasconcelos LHC, de Souza ILL, Silva ADS, Silva TMG, et al. Toxicological, Antidiarrheal, and Spasmolytic Activities of Solanum paniculatum. Planta Med. 2016; 82:58-64.

12. Obade E, Ilesanmi OB, Crown O, Akinmoladun AC, Olaleye MT, Akindahunsi AA. Neuromodulatory effect of solvent fractions of Africa eggplant (Solanum dadyphyllum) against $\mathrm{KCN}$-induced mitochondria damage, viz. NADH-succinate dehydrogenase, $\mathrm{NADH}$ - cytochrome $\mathrm{c}$ reductase, and succinate-cytochrome $\mathrm{c}$ reductase. Clin Phytosci. 2018;4(9):1-9.

13. Li X, He G, Mu X, Xu B, Tian S, Yu X, et al. Protective effects of baicalein against rotenone-induced neurotoxicity in PC12 cells and isolated rat brain mitochondria. Eur J Pharmacol. 2012;674:227-33.

14. Sherer TB, Betarbet R, Testa CM, Seo BB, Richardson JR, Kim JH, et al. Mechanism of toxicity in rotenone models of Parkinson's disease. J Neurosci. 2003;23(34):10756-64.

15. Swarnkar S, Tyagi E, Agrawal R, Singh MP, Nath C. A comparative study on oxidative stress induced by LPS and rotenone in homogenates of rat brain regions. ETAP. 2009;27:219-24.

16. Okhawa H. Assay for lipid peroxide in animal tissues by Thiobarbituric acid reaction. Annu Rev Biochem. 1979;95:351-2.

17. Levine RL, Garland D, Oliver C, Amici A, Climent I, Lenz A. Determination of carbonyl content in oxidatively modified proteins. Methods Enzymol. 1990;186:464-78.

18. Ellman GL, Courtney KD, Andres V, Feather-Stone RM. A new and rapid colorimetric determination of acetylcholinesterase activity. Biochem Pharmacol. 1961;7:88-95.

19. Spinazzi M, Casarin A, Pertegato V, Salviati L, Angelini C. Assessment of mitochondrial respiratory chain enzymatic activities on tissues and cultured cells. Nat Protoc. 2012;7(6):1235-46.

20. Kollareth DMJ, Muralidhara M. Neuroprotective efficacy of a combination of Fish oil and Ferulic acid against 3-nitropropionic acid-induced oxidative stress and neurotoxicity in rats: behavioral and biochemical evidence. APNM. 2003;39(4):1-10.

21. Kchaou W, Abbès F, Blecker C, Attia H, Besbes S. 2013. Effects of extraction solvents on phenolic contents and antioxidant activities of Tunisian date varieties (Phoenix dactylifera L.). Industrial Crops Products. 2013;45:262-9.

22. Ngo TV, Scarlett CJ, Bowyer MC, Ngo PD, Vuong QV. Impact of different extraction solvents on bioactive compounds and antioxidant capacity from the root of Salacia chinensis L. J Food Qual. 2017;1:1-8.
23. Belwal T, Ezzat SM, Rastrelli L, Bhatt ID, Daglia M, Baldi A, et al. A critical analysis of extraction techniques used for botanicals: trends, priorities, industrial uses, and optimization strategies. TrAC. 2018;100:82-102.

24. Dirar AI, Alsaadi DHM, Wada M, Mohamed MA, Watanabe T, Devkota HP. 2019. Effects of extraction solvents on total phenolic and flavonoid contents and biological activities of extracts from Sudanese medicinal plants. S Afr J Bot. 2019;120:261-7.

25. Roddick JG. Steroidal glycoalkaloid nature and sequences of bioactivity. Adv Exp Med Biol. 1996;404:277-95.

26. Roddick JG, Weissenberg M, Leonard AL. Membrane disruption and enzyme inhibition by naturally-occurring and modified chacotriosecontaining Solanum steroidal glycoalkaloids. Phytochemistry. 2001; 56(6):603-10.

27. Tai BH, Doan VV, Pham Yen PH, Nhiem NX, Cuc NT, Trang DT, et al. Two new steroidal alkaloid saponins from the whole plants of Solanum nigrum. NPC. 2018;13(11):1457-60.

28. Shela MK, Patil MJ, Bhujbal SS, Chaudhari RB. Evaluation of the anticonvulsant activity of the ethanolic extracts from leaves of Excoecaria agallocha. FJPS. 2018;4(2):215-9.

29. Velmurugan BK, Rathinasamy B, Lohanathan BP, Thiyagarajan V, Weng C. Neuroprotective role of phytochemicals. Molecules. 2018; 23(2485):1-15.

30. Muralidhara GK. (2013) Neuroprotective effects of tomato seed extract against rotenone-induced oxidative impairments and neurotoxicity in mice. Toxicol Lett. 2013;221(Suppl.):S237.

31. Sudati JH, Vieira FA, Pavin SS, Mundstock D, Seeger RL, Golombieski R, et al. Valeriana officinalis attenuates the rotenoneinduced toxicity in Drosophila melanogaster. Neurotoxicology. 2013;37:118-26

32. Thakur P, Nehru B. Long-term heat shock proteins (HSPs) induction by carbenoxolone improves hallmark features of Parkinson's disease in a rotenone-based model. Neuropharmacol. 2013;79C:190-200.

33. Betarbet R, Canet-Aviles RM, Sherer TB, Mastroberardino PG, McLendon $\mathrm{C}, \mathrm{Kim} \mathrm{JH}$, et al. Intersecting pathways to neurodegeneration in Parkinson's disease: effects of the pesticide rotenone on DJ-1, alpha-synuclein, and the ubiquitin-proteasome system. Neurobiol Dis. 2006;22(2):404-20.

34. Joseph D, Muralidhara KM. Enhanced neuroprotective effect of fish oil in combination with quercetin against3-nitropropionic acidinduced oxidative stress in rat brain. Prog Neuro-Psychopharmacol Biol Psychiatry. 2013;40:83-92.

35. Muralidhara CG. Neuroprotective effect of aqueous extract of Selaginella delicatula as evidenced by abrogation of rotenoneinduced motor deficits, oxidative dysfunctions, and neurotoxicity in mice. Cell Mol Neurobiol. 2013;33:929-42.

36. Yankuzo HM, Baraya YS, Mustapha Z, Wong KK, Yaacob NS. Immunomodulatory effects of a bioactive fraction of Strobilanthes crispus in NMU-induced rat mammary tumor model. J Ethnopharmacol. 2018;213:31-7.

37. Liu Z, Zhou T, Ziegler AC, Dimitrion P, Zuo L. Oxidative stress in neurodegenerative diseases: From molecular mechanisms to clinical applications. Oxi Med Cell Longev. 2017;ID 2525967:1-11.

38. Moreira PI, Zhu X, Wang X, Lee H, Nunomuro A, Petersen RB, et al. Mitochondria: a therapeutic target in neurodegeneration. $B B A$. 2010;1802:212-20.

39. Ilesanmi OB, Akinmoladun AC, Olayeriju OS, Saliu IO, Olaleye MT, Akindahunsi AA. Modulation of key biochemical markers relevant to stroke by Antiaris africana leaf extract following cerebral ischemia/reperfusion injury. Afr J Tradit Complement Altern Med. 2017;14(4):253-64.

40. Pandey S, Singh B, Khan MMAA, Mahdi AA. Pharmacological profile of Bacopa monnieri: An approach to prevention and treatment of diseases. Herb Med Mod Drug Discovery. 2017;189-204.

41. Sandler M, Glover S. Neurotoxins and monoamine oxidase B inhibitors: possible mechanisms for the neuroprotective effect of (y“) deprenyl. Inhibitors of Monoamine Oxidase B.1993:169-81.

42. Dalle-Donne I, Scaloni A, Giustarini D, Cavarra E, Tell G, Lungarella G, Colombo R, et al. 2005. Proteins as biomarkers of oxidative/ nitrosative stress in diseases: the contribution of redox proteomics. Mass Spectrom Rev. 2005;24:55-99. 